Ferreira MT, Neves MJ, Wasterlain SN. 2013. Lagos leprosarium (Portugal): evidences of disease. Journal of Archaeological Science, 40: 2298-2307 (http://dx.doi.org/10.1016/j.jas.2012.12.039).

\title{
Lagos leprosarium (Portugal): evidences of disease
}

Maria Teresa Ferreira ${ }^{a}$, Maria João Neves ${ }^{\mathrm{b}}$, Sofia N. Wasterlain ${ }^{\mathrm{c},}$ *

a iDryas-GAPlab, Grupo Dryas Octopetala, Rua Aníbal de Lima, 170, 3000-030 Coimbra/ Forensic Sciences Centre, Portugal, teresa.ferreira@dryas.pt

b iDryas-GAPlab, Grupo Dryas Octopetala, Rua Aníbal de Lima, 170, 3000-030 Coimbra/ Centro de Investigação em Antropologia e Saúde, Portugal, mjoao.neves@dryas.pt

c Centro de Investigação em Antropologia e Saúde, Department of Life Sciences, University of Coimbra, 3001-401 Coimbra, Portugal, sofiawas@antrop.uc.pt

*Corresponding author: Sofia N. Wasterlain, Centro de Investigação em Antropologia e Saúde, Departamento de Ciências da Vida, Universidade de Coimbra, 3001-401 Coimbra, Portugal Telephone: +351239854105 Fax: +351239854129

E-mail address: sofiawas@antrop.uc.pt 


\begin{abstract}
In 2009, an archaeological intervention in the Valle da Gafaria (Lagos, Portugal) allowed the excavation of part of a leprosarium and an associated necropolis $\left(15^{\text {th }}-17^{\text {th }}\right.$ centuries $)$. The individuals recovered were buried directly in the soil, in positions and orientations discordant to the prevailing Christian rules. The sample is made up of eleven adult individuals of both sexes.

This paper discusses the differential diagnosis of unusual and distinct pathological changes in five of the individuals recovered. The differential diagnosis of the lesions gave rise to several possible pathological conditions, namely, leprosy, treponematosis, brucellosis, slipped femoral capital epiphysis, and Legg-Calvé-Perthes disease. Various macroscopic and radiological aspects led us to consider leprosy as the most probable diagnosis in two individuals. Treponematosis and brucellosis were the probable diagnosis in other two individuals, respectively. One individual presented lesions in the right femur compatible with Legg-Calvé-Perthes disease.

Historical documents suggest that the poor, mentally disabled, and people suffering from syphilis, tuberculosis, among others, were also housed in leprosaria. Therefore, it is possible that evidence of other conditions is found in human remains uncovered at a leprosarium.

The cases under study enrich the scanty osteoarchaeological documentation of paleopathology in Portugal in the Modern Age, namely of leprosy, brucellosis, treponematosis, and Legg-Calvé-Perthes disease, and they can contribute to reduce the discrepancy between historical and biological evidences of disease.
\end{abstract}

Key words: Leprosarium; leprosy; syphilis; brucellosis; Legg-Calvé-Perthes disease; Portugal. 


\section{Introduction}

In 2009, during the construction of a subterranean car park at the Valle da Gafaria (“Leprosarium Valley”), Lagos (Algarve, Portugal), several buildings and a cemetery were discovered. Until now, the Lagos's leprosarium was only known from historical and cartographic documents, which refer that in 1490 Lagos's residents began to pay a tax for its construction (Corrêa, 1994). As in other European cities, the Lagos's leprosarium was located outside the city walls. This hospital operated until the $17^{\text {th }}$ century, when geopolitical events motivated the renewal of the city's defensive walls, imposing the demolition of several buildings (Corrêa, 1994).

The excavation of the site exposed evidences of the $17^{\text {th }}$ century demolition of the leprosarium. The burial area was found further apart. Leprosy sufferers should remain outside the city walls both in life and after death, as their burial among the healthy was forbidden since 1179's Rome Lateran Council (Reynolds and Tanner, 1983; Carmichael, 1994; O’Neil, 1993).

A geoarchaeological approach was applied in order to recover and interpret the archaeoestratigraphic complexity of the site. This careful approach revealed particular importance, especially because severe damage to the archaeological record occurred before the field operation, causing significant loss of skeletal remains and archaeological levels and structures. Unfortunately, in some cases, these damages faded our interpretation capabilities. The complete area of the Leprosy sufferers' cemetery is now unrecoverable.

Human remains belonging to eleven individuals were recovered following an archaeothanatological approach by a multidisciplinary team (Neves et al., 2011), allowing us to realize that the individuals were buried directly in the soil. The burials showed a funerary behaviour uncommon to medieval/modern Portugal. The orientation and deposition types were variable, eight of them disregarding the canonical decubitus dorsalis and west-east deposition rule typical of the Christian belief in the resurrection of the soul. 
Five individuals contain several pathological lesions both in the skull and post-cranial skeleton. The unusual and distinct pathological changes as well as the specific provenance of the individuals led us to make the differential diagnosis, which we report in this paper.

\section{Material and Methods}

The osteoarchaeological remains from Valle da Gafaria (Lagos, Portugal) belong to eleven individuals. The skeletons were recovered in various states of preservation. Unfortunately, some skeletons were partially destroyed by bulldozer action before the arrival of the archaeology team. Besides, one burial was severely damaged by tree roots.

Sex determination was made based on the morphology of the skull and hip bone (Ferembach et al., 1980) and the morphometric analysis of the long bones, the calcaneus and talus (Wasterlain, 2000). The age-at-death estimate was taken from morphologic changes in the pubic symphysis and auricular surface of the ilium (Lovejoy et al., 1985). The stature was estimated following Olivier et al. (1978).

All skeletons were macroscopically examined by the three authors at the same time and the bones radiographed through digital mammography (Mammograph General Electrics, senographe DMR, voltage: $30 \mathrm{kV}$; exposition: $56 \mathrm{mAs}$ ). Since bone is limited in its response to disease or trauma, diagnosis of the causes of pathological changes should be founded upon an accurate description of lesion types (whether they are destructive or prolific, active or remodelled, for example) and their precise location on individual bones as well as their distribution throughout the entire skeleton (Gilmore, 2008). The procedures recommended by Boldsen and Freund (2006) and Ortner (2008) were adopted. Although some lesions can be best described by a multistage sequence of changes, for the purpose of the present analysis and following the authors' recommendation, they have all been dichotomized to absent and present.

\section{Results}


The biological profile of the individuals exhumed from Valle da Gafaria leprosarium cemetery can be observed in Table 1 . The collection is made of six females, four males, and one individual of unknown sex. All individuals are adults, two of them very young with less than 25 years at time of death. Stature values range between $144.85 \pm 3.23 \mathrm{~cm}$ for individual no. 5 (female) and $167.19 \pm 3.05 \mathrm{~cm}$ for individual no. 36 (male). The poor state of preservation and/or incompleteness of the skeletons made it impossible to accomplish the complete biological profile of three individuals (numbers 1, 2 and 3). For the purpose of the present study only the five individuals presenting unusual and distinct pathological alterations are described.

\subsection{Description of the skeletons with significant pathological alterations}

$\underline{\text { Individual 2, unknown sex, adult }}$

State of preservation/completeness: the skeleton is the worst preserved of the present sample due to bulldozer's destruction before the arrival of the archaeological team. Skull, hand bones, several feet phalanges, ribs, cervical and thoracic vertebrae, scapulae, clavicles, and sternum are missing. The remaining bones are very fragmented. No teeth were recovered.

Skeletal alterations: despite the fragmentary state of the right femur, severe pathological alterations are observable in its proximal end, including head deformation, flattening, elongation (resulting in a mushroom-shaped appearance) and irregular articular surface, lack of fovea capitis for the insertion of ligament teres, extensive bone destruction as well as reactive new bone formation (Fig. 1). Besides, the femoral head is slightly displaced downwards (Fig. 1). Porosity is visible in the diaphysis of the left femur. The radiological examination demonstrates that there was not fracture on the femoral head or on the neck (Fig. 1).

\section{Individual 5, female, $25-30$ years of age}

State of preservation/completeness: relatively fair condition despite the fragmentary nature of some leg bones (femora, right tibia and fibula) and the absence of left tibia and fibula, and feet 
bones due to bulldozer action (Fig. 2). The upper right second molar and lateral incisor and the corresponding sockets were missing and damaged post-mortem, respectively. The upper right central incisor and third molar were loose and the respective sockets were destroyed post-mortem. Several teeth were lost ante-mortem (lower: second molars, right first molar and second premolar, left canine; upper: left second premolar and first molar).

Skeletal alterations: the face, arm and hand bones as well as the fragments of the right patella, tibia and fibula show unusual and distinct pathological changes (Fig. 2). The edge of the nasal aperture displays a clear and extensive rounding. The nasal spine is completely absent. Total degeneration of the alveolar process of the pre-maxilla is observed. The palate is perforated. The mandibular bone shows porosity and alveolar regression.

At distal ends of humerus, radius and ulnae, small deposits of woven bone are visible. This type of alteration presents a bilateral occurrence although not exactly symmetrical. The right ulna also shows a lytic lesion, measuring $16.91 \mathrm{~mm} \times 9.42 \mathrm{~mm}$ diameter (all measurements were taken at the greatest diameter of the perforations) situated in the posterior surface of the olecranon. Likewise, on the anterior surface of the right patella (the only one recovered) there is one lytic lesion (circa $32.86 \mathrm{~mm} \times 23.91 \mathrm{~mm}$ ). In the proximal shaft of the right tibia and fibula, on the lateral side, there are relatively large new bone deposits, but a post-mortem fracture led to the loss of a great portion of both bones, making it impossible to accomplish the palaeopathological evaluation. All carpal bones show porosity on dorsal surfaces. Three relatively smaller lytic lesions are also located on the dorsal surfaces of the right lunate $(5.63 \times 3.41 \mathrm{~mm})$, triquetal $(5.44 \times 4.52 \mathrm{~mm})$ and scaphoid $(3.71 \times 4.77 \mathrm{~mm})$. With the exception of the second right metacarpal (with no lesions), all metacarpals show porosity on the diaphysis. Deposits of woven bone formation are visible on the phalanges, being more conspicuous on the dorsal side. Finally, the phalanges of both hands present erosive process to the distal ends with osteolysis and diaphyseal thinning (Fig. 2 and 3).

Oral pathology: there was interproximal crestal cortical bone loss, exposing the underlying porous cancellous bone. There was gross root exposure around the teeth. All this is suggestive of 
periodontitis (Kerr, 1988). With respect to dental caries, both lower first premolars showed gross crown destruction, involving the loss of so much of the tooth that it is not possible to determine where the lesion was initiated.

Individual 34, male, $30-40$ years of age

State of preservation/completeness: although very well preserved and complete, some bones (left trapezium, tibia and lateral cuneiform, eleven hand and seven feet phalanges of both sides) were not recovered. The nasal bones are broken. Four teeth were lost post-mortem (lower right lateral incisor and left central incisor, upper right first molar and central incisor). The upper left second premolar and third molar as well as upper second molars were lost ante-mortem.

Skeletal alterations: on the posterior portion of the left parietal there is a large depression (measuring $21.3 \times 5.5 \mathrm{~mm}$ diameter), with signs of bone remodelling. The alveolar process of the premaxilla was atrophic (Fig. 4). The inferior surface of both maxillae shows slight porosity. Unfortunately, the post-mortem destruction of both nasal bones made the paleopathological analysis difficult (Fig. 4). In the post-cranial skeleton, the capitulum of the left humerus is slightly eroded. Both patellae show spicules of bone. At the anterior-distal portion of the left femur diaphysis, deposits of woven bone are visible $(53 \mathrm{~mm} \times 23 \mathrm{~mm})$. On the midshaft of the right tibia, signs of periostitis are found, being more conspicuous at the medial side and less visible on the lateral side. Also in the right tibia, an abnormal new bone formation can be observed at distal-antero-medial portion; and a swelling bellow the nutrient foramen. Both fibulae display lesions on the distalposterior half portions. These lytic lesions (right fibula: $16.15 \mathrm{~mm}$ x $5.01 \mathrm{~mm}$; left fibula: $17.28 \mathrm{~mm} \mathrm{x}$ $8.02 \mathrm{~mm}$ ) show central destruction with marginal formation and also sclerosis on their margins (Fig. 5). New abnormal bone formation - striated bone - can also be detected on all left fibula diaphysis. The radiograph of the right fibula shows an irregular thickening of the cortical bone and reduction of the medullar cavity (Fig. 5). The majority of hand and foot bones show lesions. Carpal and metacarpal bones and hand phalanges exhibit osteophytes and eburnation. Tarsal and metatarsal 
bones display several small lesions: spicule formation and microporosity. Metatarsals also show some signs of eburnation. Other foot phalanges (left proximal of the first toe and intermediate of the third; right proximal of the first toe, intermediate and distal of the second and third, intermediate of the fourth and distal phalanx of the fifth toe) also show eburnation, microporosity and bone spicules.

Oral pathology: the periodontal condition indicated horizontal bone loss mainly affecting the lower dental arcade. There was interproximal crestal cortical bone loss, exposing the underlying porous cancellous bone, which suggests periodontal disease (Kerr, 1988). Four teeth (lower right central incisor, left lateral incisor and second premolar, and upper left lateral incisor) showed gross carious cavities, involving the loss of so much of the teeth that it is not possible to determine whether the lesions were initiated in the crown or root, and, in each, there is a clear opening into an exposed pulp chamber. A hollow bony lesion under remodelling (10 $\mathrm{mm}$ diameter) was found in relation to the upper right second molar socket (lost ante-mortem). The interior bony walls of the cavity are well demarcated, smooth and rounded. There is no perforation into the maxillary air sinus. Another large lytic lesion (measuring $10 \mathrm{~mm}$ wide and $4 \mathrm{~mm}$ high) under remodelling was present in relation to the upper left second molar socket, which have been lost ante-mortem. The alveolar process was already very retracted and atrophic, suggesting that tooth loss occurred a long time prior to death. For both cases, although the corresponding teeth were not present, all of the reported signs suggest chronic dental apical lesions, most probably periodontal cysts (Dias and Tayles, 1997). Two smaller apical lesions were found in association to the upper left first molar (tooth present) and right first molar (lost post-mortem). In both cases, the appearance of the bony margins does not suggest a destructive bone lesion caused by a malignant tumour or by an infective process, but a slow-growing benign lesion (Dias and Tayles, 1997). In the case of the upper left first molar, the roofless pulp chamber is exposed in a large occlusal attrition facet, so that it seems reasonable to suppose that the pulp was exposed by attrition. 


\section{Individual 36 , male, $30-40$ years of age}

State of preservation/completeness: well preserved and almost complete. The only bones missing are two hand distal phalanges (of the left first finger and of the right fifth finger), and the left triquetal. All the teeth were present.

Skeletal alterations: the nasal aperture is slightly remodelled and the alveolar process is mildly recessed. The post-cranial skeleton shows lesions to the bones of the hands. The right triquetal, hamate, and capitate show very discrete lytic lesions, surrounded by pitting and new bone deposits. Small osteophytes are present in the anterior margins of the bodies of six cervical vertebrae (C1-C6). Several lytic lesions are also located on the sternum (eight on the body and seven on the manubrium), mainly on the anterior side (Fig. 6). The largest are of destruction $(15.22 \mathrm{~mm} \times 8.94 \mathrm{~mm})$ affected the anterior surface of the manubrium. No cloacal openings are visible. The radiograph of the sternum confirms the presence of multifocal lytic foci (Fig. 6). Both clavicles display lesions: the right one shows a lytic lesion on the superolateral surface (Fig. 7), and the left one exhibits porosity and spicules on the superolateral surface. The radiograph of the right clavicle reveals that the lytic lesion visible macroscopically corresponds, in fact, to a multifocal lytic foci (Figure 7).

Oral pathology: periodontal condition was fair to good. With respect to dental caries, the upper left first molar showed a gross mesial caries (a carious cavity bridges the entire crown side from the cement-enamel junction to the edge of the occlusal surface).

\section{Individual 37, female, $25-35$ years of age}

State of preservation/completeness: almost complete and in quite good condition. However, distal hand and feet phalanges, scaphoids, right trapezium, triquetal and pisiform, left navicular and cuboid, and all cuneiforms are absent. The upper jaw was not recovered. The only tooth present was the lower left canine. 
Skeletal alterations: despite the age at death, the fifth sacral vertebra is not yet fused; neither is it the sternebra 1 with the mesosternum. Both sternebra 1 and mesosternum display striated bone formation. The vertebral bodies of three lumbar vertebrae (L3-L5) show osteolytic lesions on the superoanterior angle (Fig. 8). In the radiograph of the vertebrae (Fig. 8) the Sign of Pedro-Pons is clearly visible. The diaphysis of both fibulas exhibit swelling. On the malleolus and diaphysis of the right tibia (medial side), slight periostitis is found.

\section{Discussion}

For a differential diagnosis, we must consider a number of diseases that may produce the same skeletal lesions as observed in our sample, namely, treponematosis, brucellosis, and leprosy. Other diagnostic options, like tuberculosis, osteomyelitis, smallpox, and mycosis, were excluded, being the reasoning presented in the supplementary online material. Besides, the exuberant nature and rareness of the lesions presented by one femur (individual no. 2), as well as the scarcity of reports in the palaeopathological literature, led us to make the differential diagnosis. The conditions considered in this case were slipped femoral capital epiphysis and Legg-Calvé-Perthes' disease.

\section{Slipped femoral capital epiphysis versus Legg-Calvé-Perthes disease}

Because bone manifestations in slipped femoral capital epiphysis and Legg-Calvé-Perthes disease can overlap it is helpful to review the two diseases together. Slipped femoral capital epiphysis is a condition characterized by an inferior-posterior displacement of the femoral capital epiphysis, fusing with the neck in that position. It occurs during the rapid growth of adolescence, being rare under age 8 or over 17 years. Boys are more affected than girls (2.5:1). The condition is bilateral in only $25 \%$ of the cases and simultaneous involvement is observed in no more that about 10\% (Aufderheide and Rodríguez-Martín, 1998). There is some evidence of an underlying genetic factor, but trauma, the adolescent growth spurt and obesity are contributing factors. The primary pathology of this lesion is a stress fracture between the metaphyseal side of the growth plate and the 
neck of the femur. This allows medial posterior and downward displacement of the head of the femur which may lead to some degree of aseptic necrosis in the epiphyseal bone. Because the growth plate remains with the epiphysis, the bone of the epiphysis does not change much, except in cases with extensive aseptic necrosis. The proximal end of the femoral neck, however, presents irregularities due to the fracture, subsequent abrasion and resorption. With healing, the head, united with the neck in the slipped position, shows some dislocation of the centre of the head toward the axis of the neck. The femoral neck is almost non-existent on the superior aspect and greatly shortened inferiorly. Early and severe degenerative arthritis can occur. Occasionally, upward dislocation of the femur is observed to stimulate a new "acetabulum" on the lateral aspect of the ilium, while the head is held in the anatomical acetabulum by the ligamentum teres (Ortner, 2003).

Legg-Calvé-Perthes disease is osteochondrosis of the femoral head in children (Aufderheide and Rodríguez-Martín, 1998; Smrčka et al., 2009). It is generally accepted that this condition is produced by avascular necrosis caused by an interruption of the blood flow that reaches the epiphysis of the femoral head, especially the blood supplies from the upper and lower retinacular arteries (Aufderheide and Rodríguez-Martín, 1998; Ortner, 2003; Smrčka et al., 2009; Herrerín and Garralda, 2012). This avascular necrosis may have many different causes and the initial ischaemic episode which stops normal vascularisation is often of unknown aetiology (Smrčka et al., 2009; Herrerín and Garralda, 2012). It affects children from 3-10 years of age. Cases over age 12 are considered adolescent avascular necrosis and have a worse prognosis. As in most other osteochondroses, boys are more affected than girls (4:1) (Aufderheide and Rodríguez-Martín, 1998; Ortner, 2003). The disease is usually unilateral; in the $10 \%$ of bilateral cases the onset in the two sides does not occur at the same time but successively at an interval of 2-4 years between them. The superior and anterolateral aspects of the femoral head are the most affected, showing deformation, flattening and widening. The final result is frequently described as a 'mushroom-shaped' femoral head that is commonly lower than the position of the greater trochanter. The femoral head lacks the fovea capitis for the insertion of ligament teres (Aufderheide and Rodríguez-Martín, 1998). Early 
severe degenerative arthritis modifies the appearance and can make differentiation from the end stage of slipped capital femoral epiphysis difficult (Ortner, 2003). The acetabulum is also deformed, becoming flatter, and wider, and showing an irregular articular surface (Herrerín and Garralda, 2012). If left untreated, restoration and remodelling of the bone fixes the 'mushroom' shape of the femoral head. Later an ischium varum deformation may occur with medial displacement of the ischium producing a decreased diameter of the obturador foramen (Aufderheide and RodríguezMartín, 1998).

The pathological alterations observed in the right femur of the individual no. 2 are consistent with Legg-Calvé-Perthes' disease. Part of the femoral head was damaged post-mortem, although enough remains to indicate the nature of the pathology. The femoral head is deformed and flattened, mushroom-shaped, with a porous surface and it is slightly displaced downwards. There is extensive bone destruction as well as reactive new bone formation. Finally, the possibility of Perthes' disease is also favoured by the inexistence of a well-defined depression for ligamentum teres. Slipped capital femoral epiphysis was excluded also due to the rather normal femoral neck length. The radiological examination (Fig. 1) demonstrates that there was not fracture on the femoral head nor on the neck, which could suggest a possible traumatic origin of this pathology. Although the bone lesions observed in the individual no. 2 are consistent with a diagnosis of Perthes' disease, congenital dislocation of the hip disease cannot be completely discarded due to the fragmentary state of the pelvic bone which made it impossible to accomplish the paleopathological evaluation.

\section{Treponematosis}

Treponematosis is a chronic or subacute infection caused by spirochetes of the genus Treponema. On the basis of clinical and geographic variation, treponemal disease is divided into four types: venereal syphilis, bejel, yaws and pinta (Aufderheide and Rodríguez-Martín, 1998; Ortner, 2008; Waldron, 2009; Cook and Powell, 2012). Pinta is the most geographically restricted of the four syndromes. It is limited to the tropical regions of America. Yaws affects especially those 
populations with a low level of hygiene in tropical and subtropical humid areas. Bejel is present in rural populations in temperate and subtropical nonhumid regions. Venereal syphilis is the most ubiquitous of the four syndromes, occurring primarily in urbanized populations in all geographic regions (Aufderheide and Rodríguez-Martín, 1998). Syphilis is a sexually transmitted disease with an age of onset that tends to be in late adolescence or early adulthood. Yaws and bejel normally are not sexually transmitted and in most cases are acquired in childhood through transmission between an infected child and another child via open wounds or sores (Ortner, 2008).

All of these diseases are characterized by self-limited, primary and secondary lesions, a clinically disease-free latent period and late lesions that are frequently destructive, particularly of bone and skin, with the exception of pinta, which never involves internal organs or bones (Aufderheide and Rodríguez-Martín, 1998; Cook and Powell, 2012). The involvement of the skeleton tend to be associated with inflammatory bony changes accompanied by extensive bone regeneration, often resulting in alteration of the bone morphology (Rubini and Zaio, 2009; Waldron, 2009). The skull vault, forearm and lower leg are the favourite sites in all three syndromes. The typical appearance of skull vault lesions is caries sicca, a crater-like lesion with a central destructive focus and reactive, compact bone formation on the margins of the lesion (Aufderheide and Rodríguez-Martín, 1998; Ortner, 2003, 2008). In some cases destruction of the nasal-palatal area may occur (Rubini and Zaio, 2009). The rhinomaxillary lesions may be similar to leprosy although destructive remodelling of the alveolar process is not a common manifestation (Ortner, 2003, 2008; Rubini and Zaio, 2009). Even though the nasal cavity is often enlarged, producing the characteristic "saddle nose', the nasal spine is usually spared (Waldron, 2009). Reactive bone formation on the diaphyseal long-bone surface characterizes the abnormalities apparent in the appendicular skeleton but can also be found in the axial skeleton. In the long bones, clavicle, ribs and sternum destructive lesions or a destructive focus surrounded by bone formation may occur. This needs to be distinguished from a failure to form bone in the central focus of a bone-forming lesion, which also occurs in treponematosis and is usually found in the long bones. Clavicular involvement is 
uncommon in other systemic skeletal infectious diseases. Lesions of the tibia can motivate reactive bone formation that usually involves compact bone. The anterior location of the reactive bone gives rise to the appearance of anterior bowing. However, no bowing occurs in adult manifestations of acquired syphilis. The basic pattern of skull vault, forearm and tibia/fibula involvement is virtually pathognomic of treponematosis. However, one can have skull lesions without postcranial involvement and vice versa (Ortner, 2008).

Since pinta, yaws and bejel are geographically restricted to regions distinct from the one under analysis they are not considered as possible diagnosis in the present cases. Regarding syphilis, the individual no. 36 exhibited many of the morphological features of this condition. Although the typical appearance of skull vault lesions (caries sicca) is absent, the destructive lesions on sternum and clavicles are apparent in Figures 6 and 7, respectively. The radiographs of both bones reveal the presence of multifocal lytic foci (Fig. 6 and 7). Moreover, this individual revealed alterations in the rhinomaxillary region, with nasal aperture slightly remodelled and the alveolar process mildly recessed. Following Ortner (2008), the individual no. 36 probably suffered from syphilis (Table 2).

\section{Brucellosis}

Brucellosis is a zoonotic infection caused by gram-negative bacteria of the genus Brucella, (Aufderheide and Rodríguez-Martín, 1998; Capasso, 1999; Roberts and Manchester, 2005;

Waldron, 2009). The majority of cases affecting humans are related to Brucella melitensis, which is widely accepted as the most virulent of the Brucella spp., and whose main animal vector is the goat (Curate, 2006). This chronic disease affects the skeleton (Capasso, 1999; Ortner, 2003, 2008; Roberts and Manchester, 2005). Some authors (Capasso, 1999) find articular or osteo-articular localizations of brucellae very frequent, considering them obligatory. However, others (Aufderheide and Rodríguez-Martín, 1998; Roberts and Manchester, 2005) report that only around 10\% of people with the infection will develop bone changes. These are the result of spread of the infection via the 
bloodstream, starting in the bone marrow. They include degeneration of the joints (especially the hip and the knee), the sacroiliac joint and the interphalangeal joints of the hands, and the involvement of the spine, or brucellar spondylitis/anterior vertebral epiphysitis (Capasso, 1999; Roberts and Manchester, 2005; Ortner, 2008; Waldron, 2009). The most typical localization is at the vertebral column, affecting particularly the lower thoracic and lumbar spine, where the spinal ligaments, intervertebral discs and vertebral bodies are involved. The antero-superior vertebral area is destroyed in the annulus fibrosus of the disc, producing an osteolysis (Capasso, 1999; Roberts and Manchester, 2005). The plate opposite the one affected by the osteolysis is never affected (Capasso, 1999). Brucellosis is also associated with large lytic lesions that have marginal sclerosis. The primary sites for these lesions are the spine and the sacro-iliac joint, but they can occur in other areas of the skeleton. Unlike tuberculosis, vertebral lesions in brucellosis often involve multiple vertebrae that are not contiguous, and the vertebral arch is also a common site of involvement (Ortner, 2008).

The pathological alterations observed in the lumbar region of the individual no. 37 seem attributable to brucellosis (Fig.8). Three vertebrae show lytic lesions in the superoanterior portion of the body, similar to the brucellar epiphysitis described by Etxeberria (1994), Capasso (1999) and Ortner (2003). The lesions show a porous osseous structure, due to a granulomatous reaction that has become sclerotic. Another distinguishing feature of this disease is the new bone formation in the anterior surface of the vertebral body (Capasso, 1999), a feature which is discernible in these vertebrae. Besides, in the radiograph of the vertebrae (Fig. 8) the Sign of Pedro-Pons is clearly visible. This sign refers to an erosion of the superoanterior angle of vertebral body with a marginal halo of sclerotic bone. No other articular or discal surfaces, nor posterior facets, were affected. It is worthwhile to note that the three affected vertebrae are lumbar and that brucellar epiphysitis tends to affect primarily the lumbar segment of the spine (Etxeberria, 1994).

\section{Leprosy}


Leprosy, or Hansen disease, is one of the most dreadful diseases that human kind knows. Throughout history few diseases have provoked such stigma and cruelty as leprosy and it has been described as unique in its ability to generate fear (Carmichael, 1994; Lynnerup and Bolsen, 2012). Leprosy is a chronic infectious disease caused by the spread of Mycobacterium leprae, the leprosy bacillus (Stone et al 2009; Lynnerup and Bolsen, 2012).

Leprosy has a worldwide distribution, and appears to flourish best in rural environments as it did in Europe during Middle Ages (Carmichael, 1994; Aufderheide and Rodríguez-Martín, 1998; Ortner, 2003; Waldron, 2009). In addition to nonspecific health factors such as nutrition, leprosy prevalence is influenced greatly by apparent organism virulence as well as the cross-reaction effects of exposure to mycobacterial antigen by infection with M. tuberculosis (Carmichael, 1994; Aufderheide and Rodríguez-Martín, 1998). There is a long interval between infection and the appearance of symptoms (Matos, 2009).

The response by the body to $M$. leprae is among the most variable of any infectious disease (Ortner, 2003).The clinical forms of leprosy, tuberculoid or lepromatous, are influenced by the immunological status of the patient, and intermediate or borderline forms can occur (Carmichael, 1994; Matos, 2009; Lynnerup and Bolsen, 2012).

Bone changes in leprosy can be consequence of local tissue invasion by the bacilli, involvement of the nerves with motor and sensory loss, or circulatory disturbances producing local gangrene (Aufderheide and Rodríguez-Martín, 1998; Ortner, 2003). Bone involvement is usually secondary to the peripheral neuropathy (Matos, 2009).

The characteristic skeletal lesions in leprosy are different from the typical type and distribution of lesions in other infectious diseases and often involve the face (rhinomaxillary remodelling) and the distal appendicular skeleton (Andersen and Manchester, 1992; Ortner, 2008; Matos, 2009). In the face, the margins of the pyriform aperture tend to be rounded and usually, although not always, enlarged, and the anterior nasal spine is destroyed in some cases (Andersen and Manchester, 1992). The anterior maxillary alveolar process associated with the premaxilla may 
also undergo a destructive remodelling that reduces the alveolar sockets and may result in the loss of the maxillary incisors (Ortner, 2003, 2008; Waldron, 2009). The skeletal changes in the rhinomaxillary syndrome are infectious and erosive (Aufderheide and Rodríguez-Martín, 1998). The rhinomaxillary complex of features is absent in tuberculoid leprosy (Andersen and Manchester, 1992). Involvement of the small bones of hands, wrist, foot and ankle is a common pattern, both in tuberculoid and lepromatous leprosy (Matos, 2009). Particularly in the hands, neurologic destruction associated with leprosy may result in severe flexion contractures of the fingers, resulting in pressure erosion of metaphyseal cortex. The tubular bones of the hands and feet also undergo destructive remodelling, typically expressed as concentric atrophy (Aufderheide and RodríguezMartín, 1998; Ortner, 2003, 2008; Waldron, 2009). This remodelling begins in the distal ends of bone and in some cases may proceed to the point where the diaphysis and even the proximal metaphysis are completely destroyed (Aufderheide and Rodríguez-Martín, 1998; Ortner, 2003, 2008). In the hands, the resorption begins in the distal phalanges and progresses proximally, occasionally including the metacarpals. In the foot, the concentric resorption starts in the proximal phalanges and distal metatarsals, often sparing the subluxed distal toes (Ortner, 2003).

The destruction of sensory nerves that occurs in some patients with leprosy is accompanied by circulatory dysfunction. Because of this abnormality, injury to the feet may provide a portal of entry for secondary infection with a poor immune response related to an inadequate vascular response. Reactive woven bone formation may be stimulated by infection, and this woven bone may undergo remodelling into compact bone. Because the primary focus of the secondary infection is typically the foot, bone involvement is greatest in the distal tibia and fibula, but it can extend well beyond the midshaft (Ortner, 2003, 2008; Matos, 2009). The involvement of the tibia and fibula is often bilateral and symmetrical (Aufderheide and Rodríguez-Martín, 1998; Matos, 2009).

The study of the paleopathological features of the skeletal sample from the Lagos's Leprosarium suggests that two individuals (no. 5 and no. 34) suffered from leprosy. Given the expression and distribution of the lesions in these two skeletons, the most likely diagnosis is 
lepromatous leprosy (Table 2). The specific bone changes known as rhinomaxillary syndrome observed in individual no. 5 (Fig. 2) and no. 34 are exclusive of lepromatous and near-lepromatous leprosy (Andersen and Manchester, 1992; Waldron, 2009).

The pathological changes observed in the individual no.5 included severe remodelling of the nasal aperture, loss of the nasal spine, thinning of the maxillary alveolar process, and perforation of the palate, all typical alterations of the rhinomaxillary syndrome (Fig. 2). Besides, the changes exhibited by the long bones (bilateral lytic lesions and/or deposits of woven bone) and the erosive lesions on the hand and foot bones (particularly severe on phalanges) are good indicators of leprosy. The concomitant presence of such lesions on individual no. 5 suggests that this woman suffered of lepromatous leprosy. In the radiograph (Fig. 3), the reduction of the medullar cavity and maintenance of cortical thickness that generally occur in leprosy are not clear. Nevertheless, this radiological finding resembles that seen in other archaeological case differentially diagnosed as leprosy (Belcastro et al., 2005).

Individual no. 34 displays similar lesions in both tibiae and fibulae as well as in hand and foot bones. However, a diagnosis of rhinomaxillary syndrome is difficult since the edge of nasal aperture was broken post-mortem.

According to Ortner (2008), the association of rhinomaxillary remodelling and appendicular involvement with abnormal bone formation and abnormal bone destruction (Table 2) provides a firm diagnosis of lepromatous leprosy. Also, Bolsen and Freund (2006) stated that the combination of rhinomaxillary lesions with post-cranial lesions on fibula and foot bones is virtually pathognomonic of leprosy. Moreover, in the individual no. 34, the greater severity of the leg (Fig. 5) and foot lesions than those in the face could indicate that the pathogenesis begun first in the extremities. Andersen and Manchester (1992) also noted that the rhinomaxillary syndrome was present only in advanced and long-standing cases of low-resistance leprosy, and such lesions usually arise later than those of the lower legs (Lynnerup and Bolsen, 2012). 


\section{Conclusion}

Portuguese historical fonts refer to more than 60 leprosaria (Carvalho, 1932). However, until 2009 the only known direct evidence of bone changes due to leprosy in Portugal came from Ermida de Santo André church cemetery nearby a leprosarium at Beja (Antunes-Ferreira and Rodrigues, 2003). The recent excavation of the Valle da Gafaria site profoundly changed this lack of osteoarchaeological evidence. This paper discusses the differential diagnosis of unusual and distinct pathological changes in five of the eleven individuals recovered from this leprosarium cemetery. Various macroscopic and radiological aspects led us to consider leprosy as the most probable diagnosis in at least two individuals (no. 5 and no. 34). Treponematosis and brucellosis were the probable diagnosis in two other individuals, no. 36 and no. 37, respectively. One individual (no. 2) presented lesions in the right femur compatible with Legg-Calvé-Perthes disease.

Considering the provenance of the skeletons, it may be surprising that so few individuals display evidence of leprosy, being other pathological conditions diagnosed instead. However, historical documents suggest that the poor, mentally disabled, and people suffering from syphilis, tuberculosis, among others, were also housed in leprosaria (Belcastro et al., 2005; Roberts and Manchester, 2005; Rubini and Zaio, 2009; Stone et al., 2009). Therefore, it is possible that evidence of other conditions that not leprosy is found in human remains uncovered at a leprosarium.

To explain the absence of significant bony lesions on the remaining individuals (six out of eleven), we must have in consideration multiple aspects, such as taphonomy, funerary practices and the fact that the skeletal involvement in leprosy, namely the severity of lesions, is highly dependent on the duration of the disease. Since the severity of bone lesions depends on the stage of development of the disease, those individuals could also have suffered from leprosy, but died before the development of noticeable skeletal damage. Besides, half of the skeletons of the Lagos's series were incomplete and very fragmented due to bulldozer action. That may be the case of individual no. 2. In this specimen, Perthes' disease may correspond to the only observed lesion in a poorly preserved skeleton that potentially could or could not have suffered an additional disease. For this 
reason, the original frequency of lesions suggesting the diagnosis of leprosy cannot be rigorously ascertained.

In the paleopathological literature, all the conditions here diagnosed are rarely reported. In non-identified Portuguese human skeletal remains, there are no published cases of treponematosis or Legg-Calvé-Perthes disease. With respect to brucellosis, two possible cases were described (Curate, 2006). Regarding leprosy, it was reported only once (Antunes-Ferreira and Rodrigues, 2003). Hence, we believe the cases under study enrich the scanty osteoarchaeological documentation of paleopathology in Portugal in the Modern Age, and they can contribute to reduce the discrepancy between historical and biological evidences of disease.

\section{Acknowledgements}

The fieldwork was funded by FuturLagos, S.A. This research was carried out with financial support from Fundação Calouste Gulbenkian. The authors thank the Clínica Universitária de Imagiologia do Centro Hospital da Universidade de Coimbra, Centro de Investigação em Antropologia e Saúde, Dryas Arqueologia Lda., Alexandra Costa and Marta Tavares.

\section{References}

Andersen, J.G., Manchester, K., 1992. The rhinomaxillary syndrome in leprosy: a clinical, radiological and palaeopathological study. International Journal of Osteoarchaeology 2, $121-129$.

Antunes-Ferreira, N., Rodrigues, A.F. 2003. Intervenção A<rqueológica no Largo da Ermida de santo André (Beja). Al-Madan, II ${ }^{\mathrm{a}}$ série, 12, 193.

Aufderheide, A.C., Rodríguez-Martín, C. 1998. The Cambridge Encyclopedia of Human Paleopathology. Cambridge University Press, Cambridge. 
Belcastro, M.G., Mariotti, V., Facchini, F., Dutour, O. 2005. Leprosy in a skeleton from the $7^{\text {th }}$ century necropolis of Vicenne-Campochiaro (Molise, Italy). International Journal of Osteoarchaeology 15, 431-448.

Bolsen, J.L., Freund, U.H. 2006. Osteological leprosy - epidemiology and diagnosis. Scandinavian Journal of Forensic Sciences 2, 1-24.

Capasso, L. 1999. Brucellosis at Herculaneum (79 AD). International Journal of Osteoarchaeology $9,277-288$

Carmichael, A.G. 1994. Leprosy. In: Kiple, K.F. (Ed.), The Cambridge World History of Human Disease. Cambridge University Press, Cambridge, pp. 834-839.

Carvalho, A.S. 1932. História da Lepra em portugal. Sociedade de Papelaria, Porto.

Cook, D.C., Powell, M.L. 2012. Treponematosis: Past, Present and Future. In: Grauer, A.L. (Ed.), A Companion to Paleopathology. Wiley-Blackwell, Malden, MA, pp. 472-491.

Corrêa, F.C. 1994. A cidade e o termo de Lagos no período dos reis Filipes. Centro de Estudos Gil Eanes, Lagos.

Curate, F. 2006. Two possible cases of brucellosis from a Clarist monastery in Alcácer do Sal, southern Portugal. International Journal of Osteoarchaeology 16, 453-458.

Dias, G., Tayles, N. 1997. 'Abscess cavity’ - a misnomer. International Journal of Osteoarchaeology 7, 548-554.

Etxeberria, F. 1994. Vertebral epiphysitis: early signs of Brucellar disease. Journal of Paleopathology 6, 41-49.

Ferembach, D., Schwidetzky, I., Stloukal, M. 1980. Recommendations for age and sex diagnosis of skeletons. Journal of Human Evolution 9, 517-550.

Gilmore, J.K. 2008. Leprosy at the Lazaretto on St Eustatius, Netherlands Antilles. International Journal of Osteoarchaeology 18, 72-84. 
Herrerín, J., Garralda, M.D. 2012. Legg-Calvé-Perthes disease and unifocal eosinophilic granuloma in a Visigoth from the Duratón Necropolis (Segovia, Spain). International Journal of Osteoarchaeology 22, 86-97.

Kerr, N.W. 1988. A method of assessing periodontal status in archaeologically derived skeletal material. Journal of Paleopathology 2, 67-78.

Lovejoy, C., Meindl, R., Pryzbeck, T., Mensforth, R. 1985. Chronological metamorphosis of the auricular surface of the ilium: a new method for the determination of adult skeletal age at death. American Journal of Physical Anthropology 68, 15-28.

Lynnerup, N., Bolsen, J. 2012. Leprosy (Hansen's disease). In: Grauer, A.L. (Ed.), A Companion to Paleopathology. Wiley-Blackwell, Malden, MA, pp. 458-471.

Matos, V. 2009. O diagnóstico retrospectivo da lepra: complementaridade clínica e paleopatológica no arquivo médico do Hospital-Colónia Rovisco Pais (século XX, Tocha, Portugal) e na colecção de esqueletos da leprosaria medieval de St. Jorgen's (Odense, Dinamarca). PhD Thesis on Antropology. University of Coimbra, Coimbra.

Neves, M.J., Almeida, M., Ferreira, M.T. 2011. História de um arrabalde durante os séculos XV e XVI: “o poço dos negros” em Lagos (Algarve, Portugal) e o seu contributo para o estudo dos escravos africanos em Portugal. In: Matos, A.T., Costa, J. P. (Eds.), A Herança do Infante. Câmara Municipal de Lagos, Lagos, pp. 29-46.

Olivier, G., Aaron, C., Fully, G., Tissier, G. 1978. New estimations of stature and cranial capacity in modern man. Journal of Human Evolution 7, 512-518.

O’Neill, Y.V., 1993. Diseases of the middle ages. In: Kiple, K.F. (Ed.), The Cambridge World History of Human Disease. Cambridge University Press, Cambridge, pp. 270-279.

Ortner, D.J. 2003. Identification of pathological conditions in human skeletal remains, second ed. Academic Press, San Diego. 
Ortner, D.J. 2008. Differential diagnosis of skeletal lesions in infectious disease. In: Pinhasi, R., Mays, S. (Eds.), Advances in Human Paleopathology. John Wiley \& Sons, Chichester, pp. 191-214.

Reynolds, V., Tanner, R. 1983. The biology of religion. Longman, London.

Roberts, C., Manchester K. 2005. The Archaeology of Disease, third ed. Sutton Publishing, Stround.

Rubini, M., Zaio, P. 2009. Lepromatous leprosy in an early mediaeval cemetery in Central Italy (Morrione, Compochiaro, Molise, $6^{\text {th }}-8^{\text {th }}$ century AD). Journal of Archaeological Science $36,2771-2779$.

Smrčka, V., Marik, I., Svenssonova, M., Likovsky, J. 2009. Legg-Calvé-Perthes disease in Czech archaeological material. Clinical Orthopaedics and Related Research 467, 293-297.

Stone, A.C., Wilbur, A.K., Buikstra, J.E., Roberts, C.A. 2009. Tuberculosis and Leprosy in perspective. Yearbook of Physical Anthropology 52, 66-94.

Waldron, T. 2009. Palaeopathology. Cambridge Manuals in Archaeology. Cambridge University Press, Cambridge.

Wasterlain, S.N. 2000. Morphé: análise das proporções entre os membros, dimorfismo sexual e estatura de uma amostra da Colecção de Esqueletos Identificados do Museu Antropológico da Universidade de Coimbra. Masters Dissertation on Human Evolution. Department of Anthropology, University of Coimbra, Coimbra. 